\title{
Sustained Slow-Scale Oscillation in Higher Order Current-Mode Controlled Converter
}

\author{
Siu Chung Wong, Member, IEEE, Xiaoqun Wu, and Chi K. Tse, Fellow, IEEE
}

\begin{abstract}
DC-DC converters under current-mode control have been known to exhibit slow-scale oscillation as a result of a Hopftype bifurcation as one or more of the parameters of the outer voltage loop are varied. In the absence of the outer voltage loop (i.e., open loop), slow-scale oscillation was generally not observed in simple low-order dc-dc converters, i.e., buck, buck-boost, and boost converters. In this paper, slow-scale bifurcation in a higher order current-mode controlled converter is studied. It has been found experimentally that, even in the absence of a closed outer voltage loop, a current-mode controlled Ćuk converter can exhibit a slow-scale Hopf-type bifurcation. The phenomenon was observed in a commercial low-ripple dc-dc converter which has been designed using the Cuk converter and the LM2611 controller. Such slow-scale oscillation of the inner current loop can also be observed in full-circuit SPICE simulations. An averaged model has been developed and implemented in SPICE to find the Hopf bifurcation boundaries. With this averaged model, the Hopf bifurcation can be explained conveniently using the traditional loop gain analysis. Specifically, the extra degrees of freedom in higher order dc-dc converters have opened up a new possible mode of instability which has not been found in simple low-order dc-dc converters.
\end{abstract}

Index Terms-Bifurcation, dc-dc converters, Ćuk converter, current-mode control.

\section{INTRODUCTION}

C URRENT-PROGRAMMED control, which is one of the most commonly used control schemes in dc-dc converters, has received much attention from power electronics practitioners in the past two decades [1], [2]. Recently, some nonlinear phenomena in current-mode controlled dc-dc converters have been studied [3], [4]. Generally, two distinct types of bifurcations have been identified, namely, slow-scale Hopf-type bifurcation and fast-scale bifurcation. The former can be regarded as a kind of low-frequency phenomenon which is caused by the voltage feedback loop permitting low-frequency oscillation [5]-[8]. The latter, however, is related to the inner current loop instability, and often manifests as period doubling at the switching frequency, as reported in [9], [10]. In particular, the outer voltage loop, through which low-frequency oscillation is sustained, has been found crucial to the occurrence of slow-scale Hopf-type bifurcation in current-mode controlled simple low-order dc-dc converters.

Manuscript received July 10, 2007; revised September 25, 2007. This work was supported by Hong Kong Polytechnic University under Grant A-PA2R. This paper was recommended by Associate Editor M. di Bernardo.

S. C. Wong and C. K. Tse are with the Department of Electronic and Information Engineering, Hong Kong Polytechnic University, Hong Kong (e-mail: encktse@polyu.edu.hk).

$\mathrm{X}$. Wu was with the Department of Electronic and Information Engineering, Hong Kong Polytechnic University, Hong Kong. He is now with the School of Mathematics and Statistics, Wuhan University, Hubei 430072, China.

Digital Object Identifier 10.1109/TCSII.2007.914438
Higher order dc-dc converters, such as the Ćuk converter, enable low ripple voltage and low rms current on both the input and the output sides. This is a significant advantage over other inverting topologies such as the buck-boost and flyback converters. For such higher order dc-dc converters under currentmode control, fast-scale bifurcation has been reported and analyzed [12], [13]. Previous studies have also suggested that, in the presence of the inner current loop, fast-scale period-doubling bifurcation occurs under variation of some parameters. However, slow-scale bifurcation is expected in the presence of an unstable outer voltage loop, which is consistent with results reported so far regarding slow-scale bifurcation of simple low-order dc-dc converters. In this paper, we will focus on an instability phenomenon, which has apparently been ignored in all past studies. Our initial observation was made from a commercial low-ripple dc-dc converter, the design of which has been based on a Cuk converter and the use of the LM2611 controller for output regulation. The system's inner current loop has been compensated to avoid fast-scale bifurcation. It has been observed that slow-scale Hopf-type bifurcation occurs as the equivalent reference current is increased, even in the absence of a closed outer voltage loop, i.e., with the outer voltage loop opened. Moreover, with the outer voltage loop closed, one would still expect the system to become unstable, as in all previous studies of inner loop stability for simple low-order converters.

Our study in this paper will consist of the following aspects: 1) experimental observation of slow-scale bifurcation in the Ćuk converter controlled by the LM2611 controller with the outer voltage feedback loop opened; 2) full-circuit SPICE simulations confirming that the oscillation has been originated from the inner current loop; 3 ) development of an averaged model for analysis; 4) identification of the slow-scale bifurcation boundaries; and 5) derivation of stability boundaries analytically and verification by full-circuit SPICE simulations.

\section{Current-Mode Controlled ĆUK CONVERTER}

Fig. 1(a) shows the schematic diagram of a Ćuk converter under current-mode control. Unlike other simple low-order converters, the Ćuk converter can operate in continuous conduction mode (CCM) and a number of discontinuous conduction modes [14]. At present, the dynamics of the Ćuk converter remains relatively unexplored, even for the simplest CCM operation. For simplicity, we will focus on operation in CCM, for which only two complimentary switch states are involved, i.e., the switch is closed while the diode is open, and vice versa. Provided that the sum of the inductor currents $i_{1}+i_{2}$ remains positive, the diode conducts current for the whole subinterval during which the switch is off, and the Ćuk converter maintains in CCM. Specifically, the sum of the inductor currents is the programming variable which, by comparing with the difference of the reference 


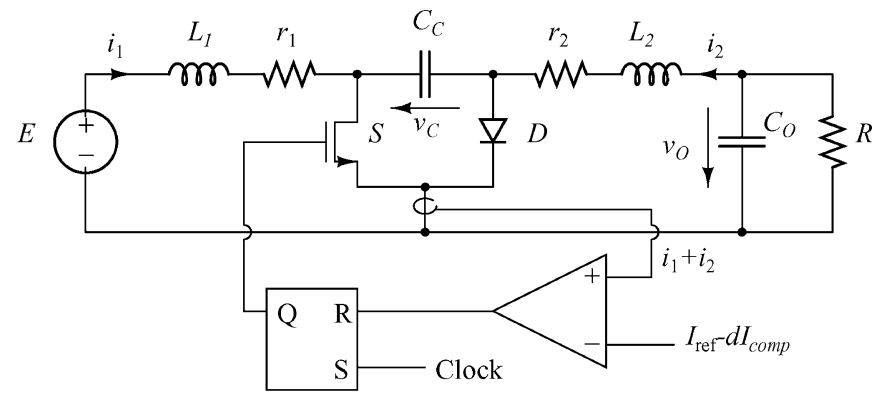

(a)

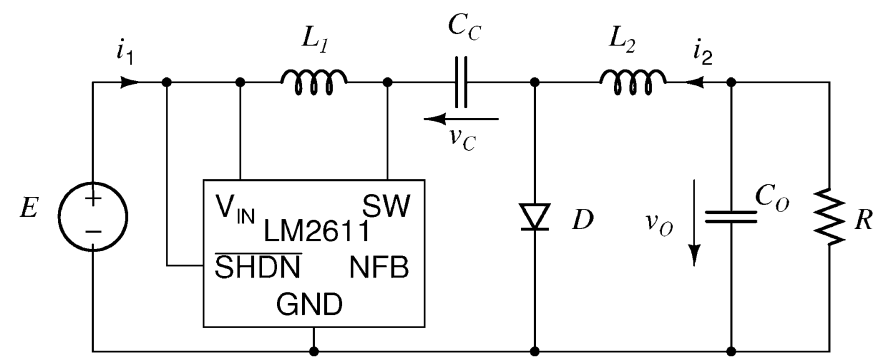

(b)

Fig. 1. (a) Current-mode controlled Ćuk converter with the outer voltage loop opened. (b) Practical circuit with LM2611 controller.

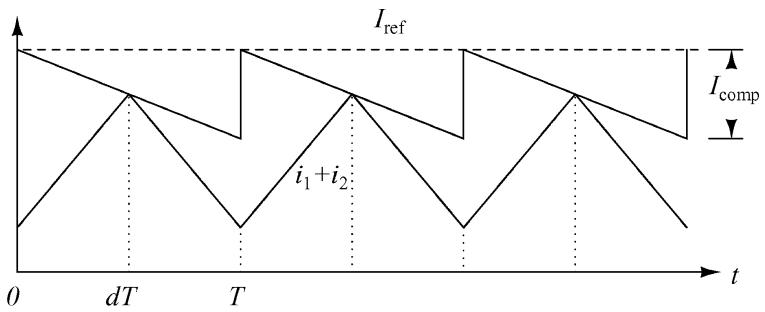

Clock
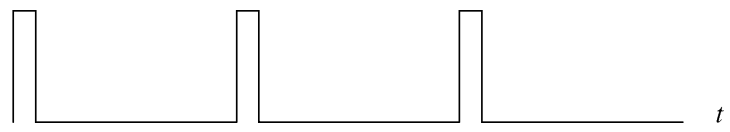

Fig. 2. Waveform of $i_{1}+i_{2}$ in current-mode controlled Ćuk converter.

current $I_{\text {ref }}$ and the compensation current $d I_{\text {comp }}$, generates the on-off driving signal for the switch, where $d$ is the duty cycle. Switch $S$ is turned on by the clock signal at the beginning of the switching period $T$, i.e., at $t=n T$ for integer $n$. The inductor currents $i_{1}$ and $i_{2}$ ramp up. As $i_{1}+i_{2}$ climbs to the value of $I_{\text {ref }}-d I_{\text {comp }}$, switch $S$ is turned off and remains off until the next cycle begins. A typical waveform of $i_{1}+i_{2}$ is shown in Fig. 2.

The problem of fast-scale period-doubling bifurcation in this type of converter circuits has been widely documented [12], [13]. Specifically, the inner current loop has been identified as the main structural cause of the observed period-doubling bifurcation. In the absence of the compensation ramp, the onset of period doubling occurs when the duty cycle exceeds 0.5 . The use of a compensation ramp, as described in Fig. 2, would stabilize the inner current loop in the sense that the critical value of the duty cycle is extended beyond 0.5 .
TABLE I

COMPONENT VALUES USED IN EXPERIMENT

\begin{tabular}{ll}
\hline Circuit Components & Values \\
\hline Input Voltage $E$ & $3.9 \mathrm{~V}$ \\
Inductance $L_{1}$ & $10 \mu \mathrm{H}$ \\
Inductance $L_{2}$ & $10 \mu \mathrm{H}$ \\
Capacitance $C_{C}$ & $1 \mu \mathrm{F}$ \\
Capacitance $C_{O}$ & $20 \mu \mathrm{F}$ \\
Load Resistance $R$ & $25 \Omega$ \\
\hline
\end{tabular}

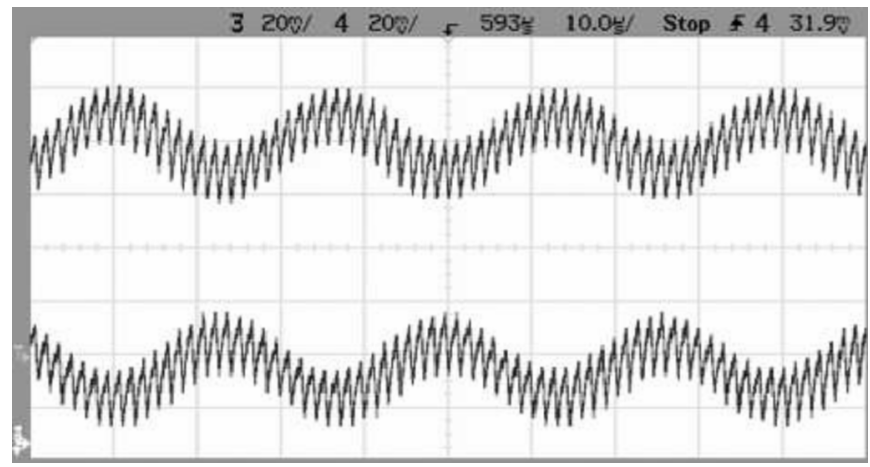

Fig. 3. Experimental slow-scale oscillations in the current-mode controlled Ćuk converter using LM2611. Upper trace: $i_{1}(200 \mathrm{~mA} / \mathrm{div})$; lower trace: $i_{2}$ (200 mA/div). Time scale is $10 \mu \mathrm{s} / \mathrm{div}$.

TABLE II

OTHER COMPONENT VALUES ESTIMATED AND USED IN SiMULATIONS

\begin{tabular}{ll}
\hline Circuit Components & Values \\
\hline Switching Frequency $f$ & $700 \mathrm{kHz}$ \\
Resistance $r_{1}$ & $0.73 \Omega$ \\
Resistance $r_{2}$ & $0.20 \Omega$ \\
$I_{\text {ref }}$ & $2.7 \mathrm{~A}$ \\
$I_{\text {comp }}$ & $1 \mathrm{~A}$ \\
\hline
\end{tabular}

\section{EXPERIMENTS AND COMPUTER SIMULATION STUDY}

We have built a Ćuk converter with LM2611, as shown in Fig. 1(b). The component values are given in Table I. Oscillatory waveforms have persistently been observed, as shown in Fig. 3, for the two inductor currents while the voltage feedback pin of LM2611 has been disconnected.

In order to confirm that the oscillation is caused by the current-loop instability rather than circuit noises or other coupling effects, we have performed SPICE simulations under an ideal circuit environment. Table II shows the additional parameters used in simulation. The switching frequency used is the same as that observed from the experimental current waveforms. The equivalent resistances $r_{1}$ and $r_{2}$ are estimated from the data sheets of LM2611 and the components used. The corresponding simulated inductor current waveforms are shown in Fig. 4 for $I_{\text {ref }}=2.7 \mathrm{~A}$ and $I_{\text {comp }}=1 \mathrm{~A}$. We observe that the simulated and experimental waveforms are in good agreement.

As we are interested in the low-frequency behavior of the circuit, it suffices to use an averaged model for capturing low-frequency dynamics. Fig. 5 shows such a model for the Ćuk converter under study [11]. This model retains the essential low-frequency behavior, although high-frequency details would have been discarded by the averaging process. Thus, the averaged model is still expected to capture the slow-scale oscillations, as 


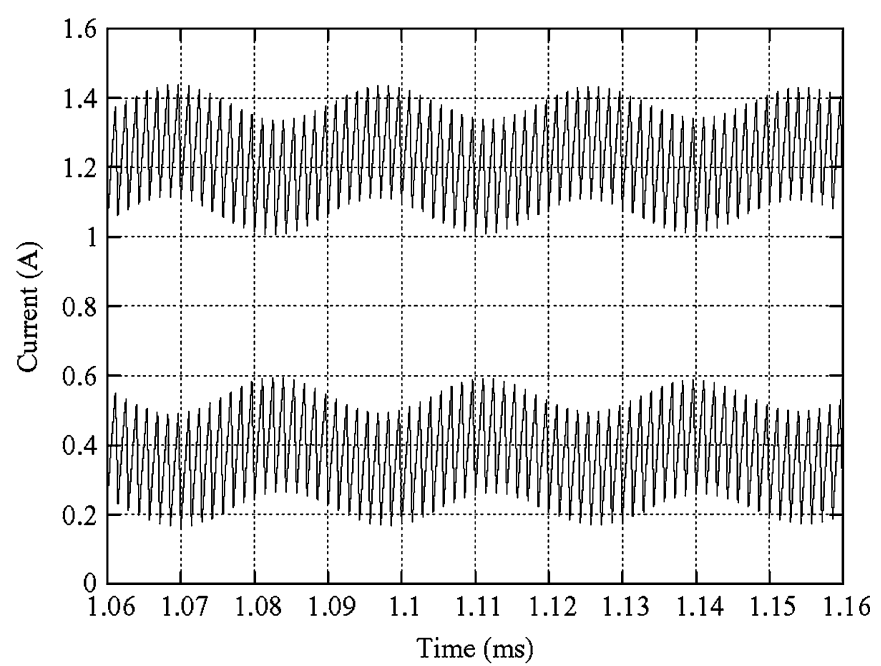

Fig. 4. Full-circuit SPICE simulated waveforms of $i_{1}$ (upper trace) and $i_{2}$ (lower trace) for the current-mode controlled Ćuk converter using LM2611 controller. Component values are given in Tables I and II.
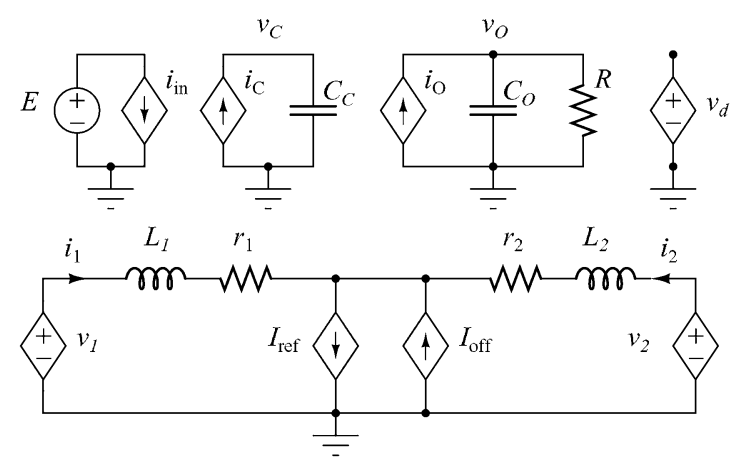

Fig. 5. SPICE averaged model for the current-mode controlled Ćuk converter. Component values are given in Tables I and II. Expressions for dependent sources are: $i_{\text {in }}=i_{1}, i_{C}=(1-d) i_{1}-d i_{2}, i_{O}=$ $i_{2}, d=v_{d}, v_{1}=E-(1-d) v_{C}, v_{2}=d v_{C}-v_{O}, I_{\mathrm{off}}=$ $(d T) /(2)\left(\left(E-i_{1} r_{r}\right) /\left(L_{1}\right)+\left(v_{c}-v_{o}-i_{2} r_{2}\right) /\left(L_{2}\right)\right)-d I_{\text {comp }}$, and $v_{d}=\left(v_{L_{1}}+v_{o}\right) /\left(E-v_{L_{2}}+v_{o}\right)$.

confirmed by the simulated waveforms shown in Fig. 6 for circuit parameters given in Tables I and II.

\section{TheORETICAL ANALYSIS OF SLOW-SCALE BIFURCATION BEHAVIOR}

From the foregoing experimental and simulation studies, we have observed current-loop induced Hopf bifurcation. Here, we will use the averaged model to analyze the bifurcation phenomenon and to locate the bifurcation boundary useful for design purposes.

First, we write the set of averaged equations describing the Ćuk converter as follows:

$$
\left\{\begin{array}{l}
i_{1}^{\prime}=-\frac{(1-d) v_{C}}{L_{1}}-\frac{i_{1} r_{1}}{L_{1}}+\frac{E}{L_{1}} \\
i_{2}^{\prime}=\frac{-v_{O}+d v_{C}}{L_{2}}-\frac{i_{2} r_{2}}{L_{2}} \\
v_{O}^{\prime}=\frac{i_{2}}{C_{O}}-\frac{v_{O}}{C_{O} R} \\
v_{C}^{\prime}=\frac{(1-d) i_{1}}{C_{C}}-\frac{d i_{2}}{C_{C}}
\end{array}\right.
$$

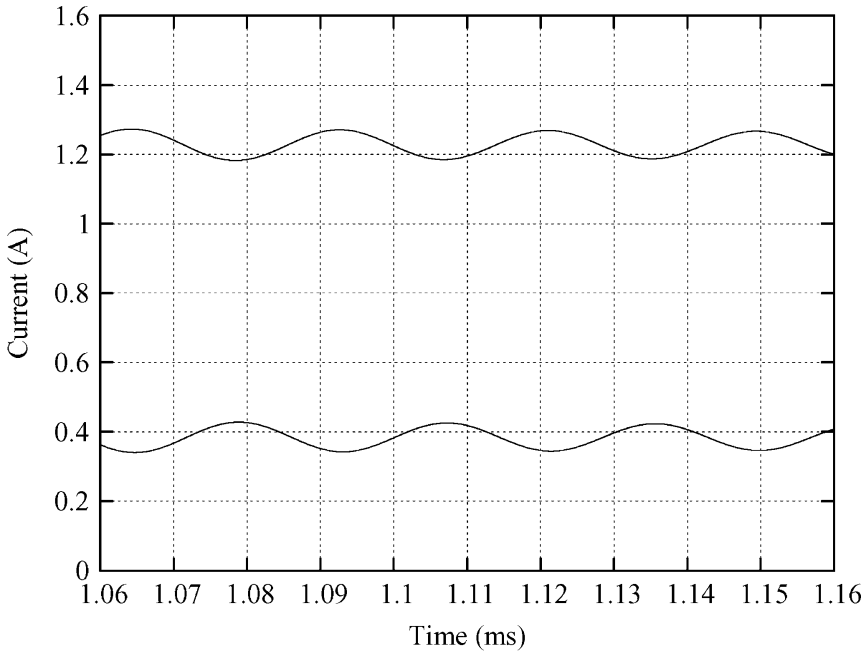

Fig. 6. SPICE averaged model simulated waveforms of $i_{1}$ (upper trace) and $i_{2}$ (lower trace) for the current-mode controlled Ćuk converter using LM2611 controller. Component values are given in Tables I and II.

where prime $\left({ }^{\prime}\right)$ denotes time derivative, and $d$ is the duty cycle which is the fraction of the switching period $T$ for which the switch $S$ is turned on.

By inspection of the circuit [Fig. 1(a)] and the waveforms (Fig. 2), the average value of $i_{1}+i_{2}$ can be expressed as

$i_{1}+i_{2}=I_{\mathrm{ref}}-\frac{d T}{2}\left(\frac{E-i_{1} r_{1}}{L_{1}}+\frac{v_{C}-v_{O}-i_{2} r_{2}}{L_{2}}\right)-d I_{\mathrm{comp}}$

It is assumed that the system is free from fast-scale currentloop instability as a result of proper application of current loop compensation, and in particular the amount of compensation is given by

$$
I_{\text {comp }}=\frac{d-0.5}{1-d} E T\left(\frac{1}{L_{1}}+\frac{1}{L_{2}}\right) .
$$

We now take the Fourier series expansion of every state variable. In general, variable $x(t)$ can be expanded as

$$
\begin{aligned}
x(t)= & \mathbf{x}_{0}+\mathbf{x}_{1} \exp (j \omega t)+\left(\mathbf{x}_{1} \exp (j \omega t)\right)^{*} \\
& +\sum_{n=2}^{\infty}\left[\mathbf{x}_{n} \exp (j n \omega t)+\left(\mathbf{x}_{n} \exp (j n \omega t)\right)^{*}\right]
\end{aligned}
$$

where superscript $*$ denotes complex conjugation, $\omega=2 \pi f$ denotes the fundamental frequency of oscillation, and $\mathbf{x}_{n}$ is the $n$th harmonic component of $x(t)$ which is given by

$$
\mathbf{x}_{n}=x_{n r}+j x_{n i}=\frac{\omega}{2 \pi} \int_{t-\frac{2 \pi}{\omega}}^{t} x(\tau) \exp (-j n \omega \tau) d \tau .
$$

Here, the dot product of two complex numbers, $\mathbf{x}_{n}$ and $\mathbf{y}_{n}$, can be defined as $\mathbf{x}_{n} \cdot \mathbf{y}_{n}=x_{n r} y_{n r}+x_{n i} y_{n i}$. Suppose $\mathbf{d}_{n}, \mathbf{v}_{\mathbf{C}_{n}}, \mathbf{i}_{\mathbf{1}_{n}}$ 


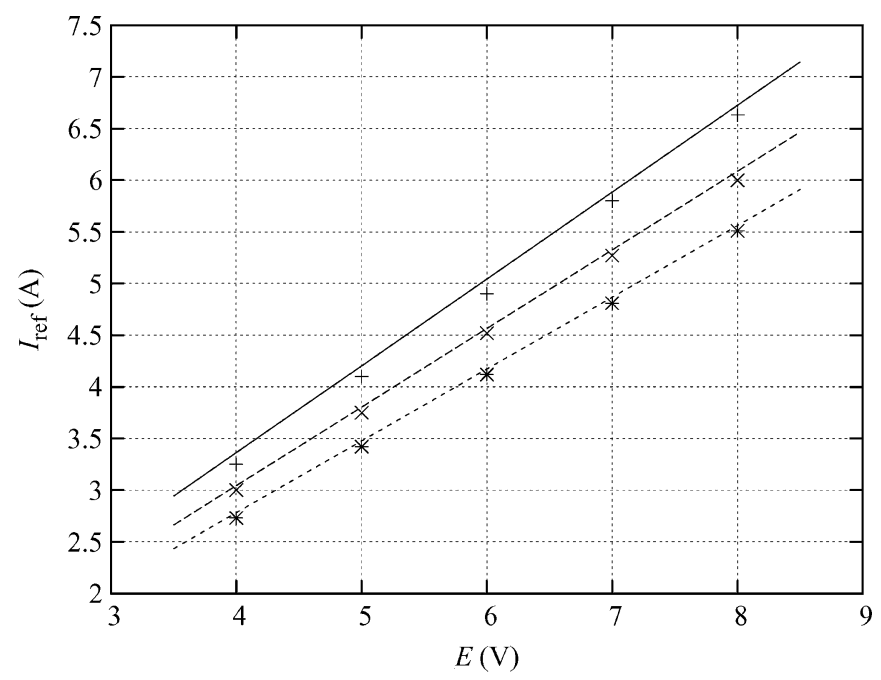

Fig. 7. Stability boundaries for different values of loading resistance: upper line for $R=25 \Omega$, middle line for $R=20 \Omega$, and bottom line for $R=15 \Omega$. Points are boundaries found from full-circuit simulations. Unstable and stable regions of operation are located above and below the line, respectively.

and $\mathbf{i}_{2 n}$ are the $n$th components of $d, v_{C}, i_{1}$ and $i_{2}$. Using (4) and (5), (1) becomes

$$
\begin{gathered}
\left\{\begin{array}{l}
L_{1} i_{1_{0}}^{\prime}=-\left(1-d_{0}\right) v_{C_{0}}+2 \mathbf{d}_{1} \cdot \mathbf{v}_{C_{1}}-i_{1_{0}} r_{1}+E \\
L_{2} i_{2_{0}}^{\prime}=-v_{O_{0}}+d_{0} v_{C_{0}}+2 \mathbf{d}_{1} \cdot \mathbf{v}_{C_{1}}-i_{2_{0}} r_{2} \\
C_{O} v_{O_{0}}^{\prime}=i_{2_{0}}-\frac{v_{O_{0}}}{R} \\
C_{C} v_{C_{0}}^{\prime}=\left(1-d_{0}\right) i_{1_{0}}-d_{0} i_{2_{0}}-2 \mathbf{d}_{1} \cdot\left(\mathbf{i}_{11}+\mathbf{i}_{21}\right)
\end{array}\right. \\
\left\{\begin{array}{c}
L_{1} i_{1_{1}}^{\prime}+j \omega L_{1} i_{1_{1}}=-\left(1-d_{0}\right) v_{C_{1}}+d_{1} v_{C_{0}} \\
-i_{1_{1}} r_{1} \\
L_{2} i_{2_{1}}^{\prime}+j \omega L_{2} i_{2_{1}}=-v_{O_{1}}+d_{0} v_{C_{1}}+d_{1} v_{C_{0}} \\
-i_{2_{1}} r_{2} \\
C_{O} v_{O_{1}}^{\prime}+j \omega C_{O} v_{O_{1}}=i_{2_{1}}-\frac{v_{O_{1}}}{R} \\
C_{C} v_{C_{1}}^{\prime}+j \omega C_{C} v_{C_{1}}=i_{1_{1}}-d_{0}\left(i_{1_{1}}+i_{2_{1}}\right) \\
\quad-\left(i_{1_{0}}+i_{2_{0}}\right) d_{1}
\end{array}\right.
\end{gathered}
$$

for $n=0$ and 1, respectively. Similarly, (2) becomes

$$
\begin{aligned}
& i_{1_{0}}+i_{2_{0}}= I_{\mathrm{ref}_{0}} \\
&-d_{0} \frac{T}{2}\left(\frac{E-i_{1_{0}} r_{1}}{L_{1}}+\frac{v_{C_{0}}-v_{O_{0}}-i_{2_{0}} r_{2}}{L_{2}}\right) \\
&-T \mathbf{d}_{1} \cdot\left(-\frac{\mathbf{i}_{1_{1}} r_{1}}{L_{1}}+\frac{\mathbf{v}_{C_{1}}-\mathbf{v}_{O_{1}}-\mathbf{i}_{2_{1}} r_{2}}{L_{2}}\right) \\
&-d_{0} I_{\text {comp }} \\
& i_{1_{1}}\left(1-\frac{d_{0} T}{2} \frac{r_{1}}{L_{1}}\right)+d_{0} \frac{T}{2} \frac{v_{C_{1}}}{L_{2}} \\
&+i_{2_{1}}\left(1-\left(\frac{R}{1+j \omega C_{O} R}+r_{2}\right) \frac{d_{0} T}{2 L_{2}}\right) \\
&=I_{\mathrm{ref}_{1}}-d_{1} I_{\mathrm{comp}} \\
&-d_{1} \frac{T}{2}\left(\frac{E-i_{1_{0}} r_{1}}{L_{1}}+\frac{v_{C_{0}}-v_{O_{0}}-i_{2_{0}} r_{2}}{L_{2}}\right)
\end{aligned}
$$

Equations (6) and (8) describe the dynamics of the dc components while (7) and (9) give the dynamics of the fundamental frequency components for the system. To test the stability of the system, we first calculate the steady-state solutions of dc components from (6) and (8) and the fundamental components from (7) and (9) for the system. The loop gain at the fundamental frequency will be calculated using the steady-state solution of (7) and (9). The stability of the system can then be tested using the Barkhausen criteria.

The steady-state solution of dc components can be obtained by setting all time-derivatives in (6) to zero and solving for $i_{1_{0}}, i_{2_{0}}, v_{C_{0}}$ and $v_{O_{0}}$. This gives

$$
\left\{\begin{array}{l}
v_{C_{0}}=\frac{\left(1-d_{0}\right)\left(R+r_{2}\right) E-r_{1}\left(R+r_{2}\right) G}{\Delta} \\
+\frac{\left[\left(1-d_{0}\right)\left(R+r_{2}\right)-d_{0} r_{1}\right] F}{\Delta} \\
i_{1_{0}}=\frac{d_{0}^{2} E+d_{0} F+\left(1-d_{0}\right)\left(R+r_{2}\right) G}{\Delta} \\
i_{2_{0}}=\frac{\Delta d_{0}\left(1-d_{0}\right) E+\left(1-d_{0}\right) F-d_{0} r_{1} G}{\Delta} \\
v_{O_{0}}=i_{2_{0}} R
\end{array}\right.
$$

where $\Delta=\left(1-d_{0}\right)^{2}\left(R+r_{2}\right)+d_{0}^{2} r_{1}, F=2 \mathbf{d}_{1} \cdot \mathbf{v}_{C_{1}}$ and $G=2 \mathbf{d}_{1} \cdot\left(\mathbf{i}_{1_{1}}+\mathbf{i}_{2_{1}}\right)$. Therefore, $d_{0}$, before the system enters the instability region, can be found by putting (10) into (8) and assuming nearly zero fundamental component magnitudes, i.e., $F \approx 0$ and $G \approx 0$.

The fundamental components at steady state can be obtained by setting all derivatives to zero in (7), giving

$$
\left\{\begin{array}{c}
\left(j \omega L_{1}+r_{1}\right) i_{1_{1}}=-\left(1-d_{0}\right) v_{C_{1}}+v_{C_{0}} d_{1} \\
\left(j \omega L_{2}+r_{2}\right) i_{2_{1}}=-v_{O_{1}}+d_{0} v_{C_{1}}+v_{C_{0}} d_{1} \\
\left(j \omega C_{O}+\frac{1}{R}\right) v_{O_{1}}=i_{2_{1}} \\
j \omega C_{C} v_{C_{1}}=\left(1-d_{0}\right) i_{1_{1}}-d_{0} i_{2_{1}} \\
\quad-\left(i_{1_{0}}+i_{2_{0}}\right) d_{1} .
\end{array}\right.
$$

The transfer functions $H_{v_{C}} \equiv v_{C_{1}} / d_{1}$ of the converter and $H_{d} \equiv d_{1} / v_{C_{1}}$ of the current programming function can be obtained by eliminating $i_{1_{1}}, i_{2_{1}}$ and $v_{O_{1}}$ from (11) and (9), respectively. We thus have

$$
\begin{aligned}
H_{v_{C}} & =\frac{v_{C_{1}}}{d_{1}} \\
& =\frac{-d_{0} v_{C_{0}} X_{1}+\left(1-d_{0}\right) v_{C_{0}} X_{2}-\left(i_{1_{0}}+i_{2_{0}}\right) X_{1} X_{2}}{d_{0}^{2} X_{1}+\left(1-d_{0}\right)^{2} X_{2}+j \omega C_{C} X_{1} X_{2}} \\
H_{d} & =\frac{d_{1}}{v_{C_{1}}} \\
& =\frac{\left(1-d_{0}\right)\left(1-\frac{d_{0} T}{2 L_{1}} r_{1}\right) X_{2}+\frac{d_{0} T}{2 L_{2}} X_{1} X_{2}-d_{0} X_{3}}{\Gamma}
\end{aligned}
$$

where

$$
\begin{aligned}
\Gamma= & \left(1-\frac{d_{0} T}{2 L_{1}} r_{1}\right) v_{C_{0}} X_{2}+v_{C_{0}} X_{3}+I_{\text {comp }} X_{1} X_{2} \\
& +\frac{T}{2}\left(\frac{E-i_{1_{0}} r_{1}}{L_{1}}+\frac{v_{C_{0}}-i_{2_{0}}\left(R+r_{2}\right)}{L_{2}}\right) X_{1} X_{2}
\end{aligned}
$$

along with $X_{1}=r_{1}+j \omega L_{1}, X_{2}=r_{2}+j \omega L_{2}+$ $(R) /\left(1+j \omega C_{O} R\right)$ and $X_{3}=X_{1}\left[1-\left(d_{0} T\right) /\left(2 L_{2}\right)\left(r_{2}+\right.\right.$ $\left.\left.(R) /\left(1+j \omega C_{O} R\right)\right)\right]$. The loop gain of the system is therefore obtained as

$$
H_{\text {loop }}=H_{v_{C}} H_{d} \text {. }
$$

Equation (14) allows us to find the slow-scale bifurcation boundary numerically in the parameter space according to the 


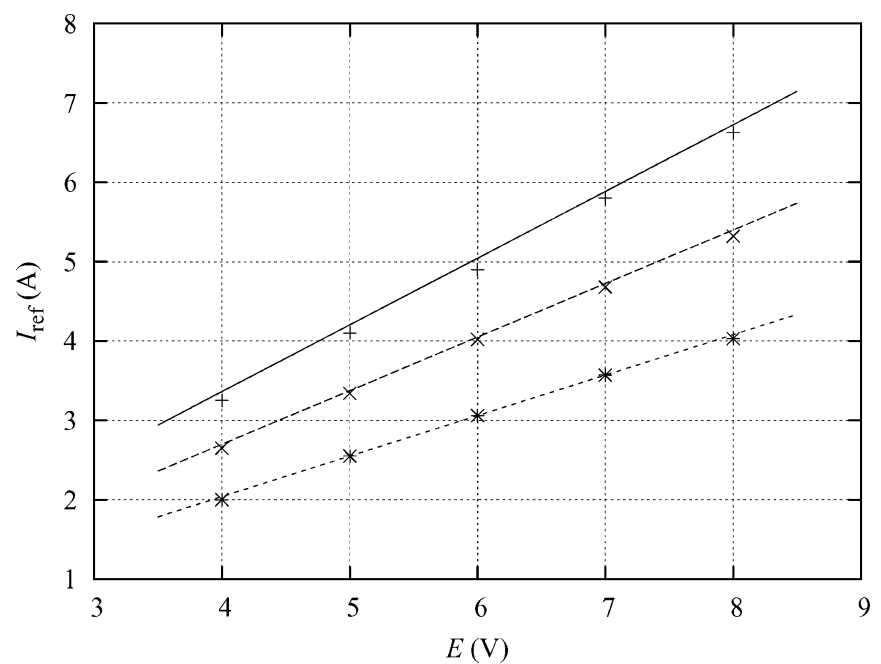

Fig. 8. Stability boundaries for different values of damping resistance: upper line for $r_{1}=0.73 \Omega$, middle line for $r_{1}=0.53 \Omega$, and bottom line for $r_{1}=$ $0.33 \Omega$. Points are boundaries found from full-circuit simulations. Unstable and stable regions of operation are located above and below the line, respectively.

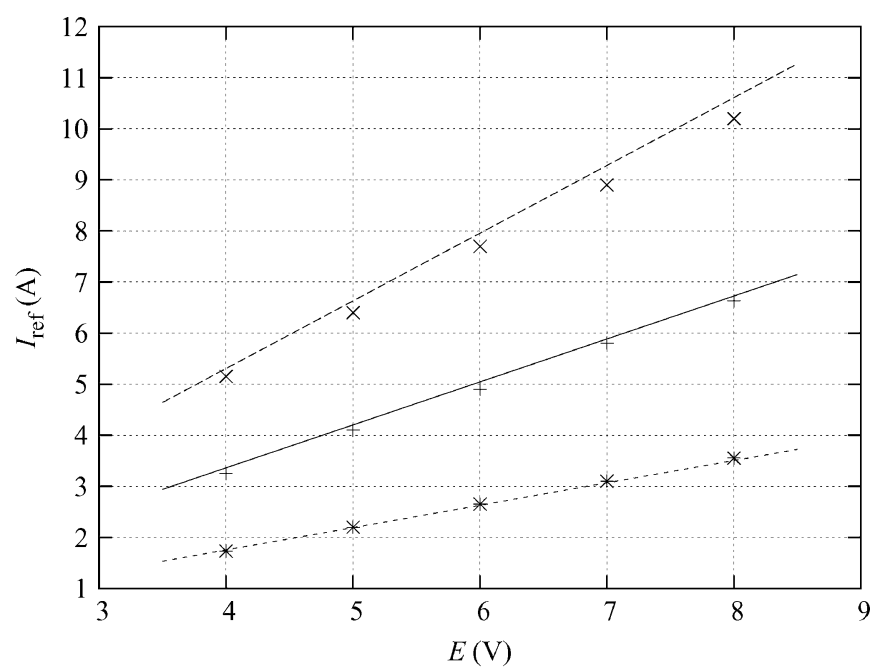

Fig. 9. Stability boundaries for different values of capacitance: upper line for $C_{C}=1.5 \mu \mathrm{F}$, middle line for $C_{C}=1.0 \mu \mathrm{F}$, and bottom line for $C_{C}=0.5 \mu \mathrm{F}$. Points are boundaries found from full-circuit simulations. Unstable and stable regions of operation are located above and below the line, respectively.

Barkhausen criteria, i.e., $\angle H_{\text {loop }}(\omega)=0$ and $\left|H_{\text {loop }}(\omega)\right|=1$ for some $\omega>0$.

It should be noted that the Barkhausen criteria do not generally give necessary and sufficient conditions for oscillations. Here, as oscillation is known to exist, the Barkhausen criteria can be conveniently used to find the conditions for oscillation.

\section{Stability Boundaries}

Of practical interest is the condition under which the system may exhibit slow-scale oscillations. Using (14), we may plot the stability boundaries for different values of $R, r_{1}$ and $C_{C}$ or for virtually any choice of parameter space. Figs. 7-9 show the specific stability boundaries corresponding to the choice of component values given in Tables I and II. Also shown in the figures are points on the stability boundaries obtained from full- circuit simulations. The excellent agreement between analysis and the full-circuit simulations clearly proves the ability of the loop-gain analysis in explaining the current loop-induced slowscale bifurcations.

\section{CONCLUSION}

A current-mode controlled Ćuk converter has been studied in this paper. For current-mode controlled simple low-order dc-dc converters, it has been commonly known that slow-scale bifurcation is caused by parameter changes of the outer voltage loop, while fast-scale bifurcation is due to the fast inner current loop. In this paper, we have demonstrated that, for higher order converters under a similar current-mode control, however, the inner current loop can induce slow-scale bifurcation in the absence of a closed outer voltage loop. The phenomenon has been analyzed using an averaged model in terms of the closed-loop stability of the inner current loop of the system. In conclusion, the extra degrees of freedom in higher order dc-dc converters have opened up a new possible mode of instability which has not been found in simple low-order dc-dc converters. In the case of the current-mode controlled Ćuk converter, slow-scale instability becomes possible even without a closed outer voltage loop.

\section{REFERENCES}

[1] R. Redl and N. Sokal, "Current-mode control, five different typs, used with the three basic classes of power converters," in IEEE Power Electron. Specialists Conf. Rec., 1985, pp. 771-785.

[2] F. D. Tan and R. D. Middlebrook, "A unified model for current-programmed converters," IEEE Trans. Power Electron., vol. 10, no. 4, pp. 397-408, Apr. 1995.

[3] S. Banerjee and G. Verghese, Nonlinear Phenomena in Power Electronics. New York: IEEE Press, 2001.

[4] C. K. Tse, Complex Behavior of Switching Power Converters. Boca Raton, FL: CRC, 2003.

[5] A. El Aroudi, L. Benadero, E. Toribio, and G. Olivar, "Hopf bifurcation and chaos from torus breakdown in a PWM voltage-controlled dc-dc boost converter," IEEE Trans. Circuits Syst. I, Fundam. Appl. Theory, vol. 46, no. 11, pp. 1374-1382, Nov. 1999.

[6] C. K. Tse, Y. M. Lai, and H. H. C. Iu, "Hopf bifurcation and chaos in a free-running current-controlled Ćuk switching regulator,", IEEE Trans. Circuits Syst. I, Fundam. Appl. Theory, vol. 47, no. 4, pp. 448-457, Apr. 2000.

[7] Z. T. Zhusubaliyev, E. A. Soukhoterin, and E. Mosekilde, "Quasi-periodicity and border-collision bifurcations in a dc-dc converter with pulsewidth modulation,", IEEE Trans. Circuits Syst. I, Fundam. Appl. Theory, vol. 50, no. 8, pp. 1047-1057, Aug. 2003.

[8] S. Maity, D. Tripathy, T. K. Bhattacharya, and S. Banerjee, "Bifurcation analysis of PWM-1 voltage-mode-controlled buck converter using the exact discrete model," IEEE Trans. Circuits Syst. I, Reg. Papers, vol. 54, no. 5, pp. 1120-1130, May 2007.

[9] H. H. C. Iu, Y. Zhou, and C. K. Tse, "Fast-scale instability in a PFC boost converter under average current mode control," Int. J. Circuit Theory Appl., vol. 31, no. 6, pp. 611-624, 2003.

[10] X. Wu, C. K. Tse, O. Dranga, and J. Lu, "Fast-scale instability of singlestage power-factor-correction power supplies," IEEE Trans. Circuits Syst. I, Reg. Papers, vol. 53, no. 1, pp. 204-213, Jan. 2006.

[11] S. C. Wong and Y. S. Lee, "SPICE modeling and simulation of hysteretic current-controlled Ćuk converter," IEEE Trans. Power Electron., vol. 8, no. 4, pp. 580-587, Apr. 1993.

[12] C. K. Tse and W. C. Y. Chan, "Chaos from a current-programmed Ćuk converter," Int. J. Circuit Theory Appl., vol. 23, no. 3, pp. 217-225, 1995.

[13] C. K. Tse, S. C. Fung, and M. W. Kwan, "Experimental confirmation of chaos in a current-programmed Ćuk converter," IEEE Trans. Circuits Syst. I, Fundam. Appl. Theory, vol. 43, no. 7, pp. 605-608, Jul. 1996.

[14] N. Femia, G. Spagnuolo, and V. Tucci, "State-space models and order reduction for dc-dc switching converters in discontinuous mode," IEEE Trans. Power Electron., vol. 10, no. 6, pp. 640-650, Jun. 1995. 